\title{
Case Report \\ Clinical Responses to Rituximab in a Case of Neuroblastoma with Refractory Opsoclonus Myoclonus Ataxia Syndrome
}

\author{
Samin Alavi, ${ }^{1}$ Ali Kord Valeshabad, ${ }^{2}$ Borhan Moradveisi, ${ }^{1}$ \\ Ali Aminasnafi, ${ }^{1}$ and Mohammad Taghi Arzanian' \\ ${ }^{1}$ Pediatric Hematology and Oncology Department, Mofid Children's Hospital, Shahid Beheshti University of Medical Sciences, \\ Tehran 15468-15514, Iran \\ ${ }^{2}$ Division of Gastroenterology and Hepatology, Johns Hopkins University, Baltimore, MD 21218, USA
}

Correspondence should be addressed to Samin Alavi, s.alavi@sbmu.ac.ir

Received 22 August 2012; Accepted 15 October 2012

Academic Editors: S. Aksoy, K. Aogi, and F. A. Mauri

Copyright (C) 2012 Samin Alavi et al. This is an open access article distributed under the Creative Commons Attribution License, which permits unrestricted use, distribution, and reproduction in any medium, provided the original work is properly cited.

\begin{abstract}
Opsoclonus myoclonus ataxia syndrome (OMS) is a rare neurologic syndrome. In a high proportion of children, it is associated with neuroblastoma. The etiology of this condition is thought to be immune mediated. In children, immunotherapy with conventional treatments such as corticosteroids, intravenous immunoglobulin, adrenocorticotropic hormone, and even antiepileptic drugs has been tried. Recently rituximab has been used safely for refractory OMS in children with neuroblastoma. Our patient was a 3.5-year-old girl referred for ataxia and dancing eye movements starting since 1.5 years ago. She was diagnosed with neuroblastoma on imaging studies on admission. The OMS was refractory to surgical resection, chemotherapy, corticosteroids, and intravenous immunoglobulin. Patient received rituximab simultaneously with chemotherapy. The total severity score decreased by $61.1 \%$ after rituximab. Patient's ataxia markedly improved that she was able to walk independently after 6 months. Our case confirmed the clinical efficacy and safety of rituximab in a refractory case of OMS.
\end{abstract}

\section{Introduction}

Opsoclonus myoclonus ataxia syndrome (OMS) is a serious, but rare immune-mediated paraneoplastic syndrome with an incidence rate of 0.18 cases per million population per year which occurs in $1.8 \%$ to $3 \%$ of patients with neuroblastoma $[1,2]$. Despite the favorable prognosis of patients with OMS associated with neuroblastoma after cure of their cancer, considerable proportions of patients are refractory and suffer long-term sequelae of this syndrome [3-6]. The recent concern is now focused to find an appropriate treatment modality for those refractory cases who do not respond to conventional treatments.

A considerable number of recent investigations confirmed OMS as a humorally mediated disease which may respond to immune suppression therapies especially those targeted to B-cell lymphocytes [7]. Rituximab, a monoclonal anti-CD20 antibody, has been reported to have favorable effects to subset refractory signs of OMS [8-12]. However, rituximab was approved for treatment of B cell non-Hodgkin lymphoma [13], it has been used for other types of autoimmune disorders [14-16]. Here we investigate the clinical responses to rituximab in a case of refractory OMS who did not respond to surgical resection of tumor and standard chemotherapy.

\section{Case}

A 3.5-year-old girl was referred to pediatric neurology department with ataxia and dancing eye movements starting since 1.5 years ago. The patient was admitted for further evaluations. Initial laboratory workups including hematological and biochemical parameters were in normal range. The 24hour urinary vanillin mandelic acid (VMA) concentration showed an increase. Imaging studies including chest and abdominal computed tomography (CT) scan revealed a tumoral lesion located in posterior mediastinum extending from T6 to T10. The patient was scheduled for thoracotomy and the mass was resected as much as possible. 
TABLE 1: Effects of rituximab on motor performance: a comparison of OMS evaluation scale scores before and after treatment.

\begin{tabular}{lcc}
\hline Scale items & Before treatment* $^{*}$ & After treatment* \\
\hline (1) Walking, side-to-side imbalance & 3 & 1 \\
(2) Walking, front-to-back imbalance & 3 & 0 \\
(3) Walking, wide base & 3 & 1 \\
(4) Instability while standing (feet apart) & 3 & 0 \\
(5) Difficulty achieving standing position & 2 & 0 \\
(6) Truncal instability while sitting & 2 & 1 \\
(7) Targeting difficulty & 3 & 1 \\
(8) Difficulty grasping with one hand & 1 \\
(9) Difficulty with pincer grasp & 2 \\
(10) Abnormal eye movements while tracking (fixation) & 2 \\
(11) Abnormal eye movements while resting & 2 \\
(12) Speech abnormality (dysarthria) & 2 & 0 \\
\hline
\end{tabular}

* Scores were from 0 to 3 (0: normal, 1: mild, 2: moderate, 3: severe).

Surgical specimens were submitted to the histopathologic laboratory. Microscopic evaluation was compatible with poor stroma, undifferentiated neuroblastoma. N-myc was amplified to more than 10 copy numbers using fluorescence in situ hybridization (FISH). Bone survey study was performed and show no abnormality. Bone marrow aspiration and whole body Tc-99 $\mathrm{m}$ was unremarkable and brain CT scan was normal.

Chemotherapy started referring to N6 protocol [17]. Within the first weeks following chemotherapy patient's symptoms and signs remarkably alleviated except opsoclonus-myoclonus syndrome which was the main complaint of the patient. It was planned to prescribe corticosteroids and clonazepam to treat the syndrome. After about 4 weeks, the debilitating problem for the patient was ataxia which showed no acceptable improvement. It was decided to prescribe intravenous immunoglobulin (IVIG) $1 \mathrm{~g} / \mathrm{Kg}$, monthly to improve ataxia and opsoclonus. After 2 courses of IVIG for 2 consecutive months, no obvious change was observed. Finally rituximab $375 \mathrm{mg} / \mathrm{m}^{2}$ as the last recognized option was considered to control patient's symptoms.

OMS Evaluation Scale was applied to evaluate clinical outcome of the patient as previously described [18]. A significant improvement in patient's ataxia and eye movements was observed after first dose of rituximab. About 3-4 weeks later the symptoms returned but with much less severity. Thus, it was decided to continue rituximab at least for 4 doses while patient was under close observation for clinical improvement. As it is shown in Table 1, based on the OMS Evaluation Scale, total severity score decreased by $61.1 \%$ after rituximab (28/36 versus 6/36). After each administration of rituximab the patient showed marked improvement; however, the symptoms again reoccurred exactly close to the next chemotherapy cycle, each time milder than previous. Patient's ataxia markedly improved to the extent that she was able to walk almost independently after 6 months. Meanwhile, it is noteworthy that the patient was in remission for her tumor at this time. The follow-up imaging studies were normal and there was no tumoral lesion after 1 year of treatment. N-Myc amplification decreased to the normal range. Considering the patient as stage 3 she was scheduled for autologous stem cell transplantation.

\section{Discussion}

For our patient, 4 weekly doses of rituximab were associated with marked clinical improvement in a refractory case to conventional treatments and also chemotherapy. Although corticosteroids and adrenocorticotropic hormone (ACTH) have been described as "gold standard" treatment for OMS [6], approximately $80 \%$ of treated patients develop longterm neurological sequelae [3]. Moreover, the relapse rate with conventional treatment is reported $75 \%[6,19]$; this rate will increase when facing refractory cases. Long-term prescription of corticosteroids and/or ACTH would be also associated with drug side effects which restrict continuation of these treatments. Thus, there has been a trend to explore further treatment options for OMS patients, especially in refractory cases.

Various combinations of drugs have been reported for treatment of OMS. Favorable outcomes have been reported for combination of dexamethasone and cyclophosphamide [6], cyclophosphamide and chemotherapy $[2,4]$, combination of ACTH, IVIG and rituximab [18], and also monotherapy with rituximab [8-11]. Ertle et al. demonstrated highdose dexamethasone pulses as an effective therapy for OMS even in cases in whom previous corticosteroid, rituximab, and cytostatic drugs were not successful [20]. In a rituximaballergic child ofatumumab, a fully humanized anti-CD20 antibody, has been examined by Pranzatelli et al. and was associated with favorable outcomes and eliminated CSF Bcell expansion [21]. OMS in our case was refractory to conventional treatments, IVIG, and also standard chemotherapy, but positive responses were observed with the first dose of rituximab.

Severity of disease based on the OMS Evaluation Scale dramatically decreased 6 months after treatment. In consistence with our result, Pranzatelli et al. also reported a case of OMS who showed marked clinical responses to rituximab 
[8]. In another study by this group rituximab was used as an adjunctive therapy to ACTH and/or IVIG. After rituximab they found that in $81 \%$ of cases lower motor severity score decreased and mean total score decreased by $44 \%$ [9].

Besides clinical responses, rituximab is associated with immunological responses in OMS. Relative B cell expansion in CSF has been proposed as a reliable biomarker for OMS [22]. Mean percentage of CD19+ B cells in CSF, but not in the serum, is higher in patients with OMS compared with controls [22]. Rituximab can afford long-term protection against CSF B cell expansion in OMS [10]; however, the main mechanism is not clear yet. Clinical effects of rituximab may be attributed to the removal of $\mathrm{B}$ cell as antigen-presenting cells than acting humorally mediated [23].

CSF/serum B-cell activation factor (BAFF) has been found to be higher in patients with untreated OMS compared with those in noninflammatory neurologic patients [24]. Pranzatelli et. al found a dramatic change in serum BAFF even after the first infusion of rituximab which revealed the probable role of BAFF in OMS activity [25]. Despite the wide investigations, the exact underlying mechanism of OMS is still unclear; moreover, the immunological pathway of rituximab is not completely diagnosed and all proposed mechanisms are just based on case reports. Prospective studies with larger sample size and adequate follow-up periods are highly recommended. It is also important to consider that the best treatment option is still under question. Since we did not perform immunological studies in our case before starting treatment with rituximab, we were not able to compare immunological changes.

\section{Conclusion}

Our case confirmed the clinical efficacy and safety of rituximab in a refractory case of OMS to surgical resection and conventional treatment.

\section{Conflict of Interests}

The authors have no conflict of interests.

\section{References}

[1] K. K. Pang, C. de Sousa, B. Lang, and M. G. Pike, "A prospective study of the presentation and management of dancing eye syndrome/opsoclonus-myoclonus syndrome in the United Kingdom," European Journal of Paediatric Neurology, vol. 14, no. 2, pp. 156-161, 2010.

[2] G. B. Aydin, M. T. Kutluk, M. Buyukpamukcu, C. Akyuz, B. Yalcin, A. Varan et al., "Neurological complications of neuroblastic tumors: experience of a single center," Child's Nervous System, vol. 26, no. 3, pp. 359-365, 2010.

[3] M. P. Gorman, "Update on diagnosis, treatment, and prognosis in opsoclonus-myoclonus-ataxia syndrome," Current Opinion in Pediatrics, vol. 22, no. 6, pp. 745-750, 2010.

[4] P. Krug, G. Schleiermacher, J. Michon et al., "Opsoclonusmyoclonus in children associated or not with neuroblastoma," European Journal of Paediatric Neurology, vol. 14, no. 5, pp. 400-409, 2010.
[5] C. E. Catsman-Berrevoets, F. K. Aarsen, M. L. C. van Hemsbergen, M. M. Van Noesel, F. G. A. J. HakvoortCammel, M. M. Van Den Heuvel-Eibrink et al., "Improvement of neurological status and quality of life in children with opsoclonus myoclonus syndrome at long-term follow-up," Pediatric Blood and Cancer, vol. 53, no. 6, pp. 1048-1053, 2009.

[6] E. de Grandis, S. Parodi, M. Conte et al., "Long-term followup of neuroblastoma-associated opsoclonus-myoclonusataxia syndrome," Neuropediatrics, vol. 40, no. 3, pp. 103-111, 2009.

[7] N. L. Antunes, Y. Khakoo, K. K. Matthay et al., "Antineuronal antibodies in patients with neuroblastoma and paraneoplastic opsoclonus-myoclonus," Journal of Pediatric Hematology/Oncology, vol. 22, no. 4, pp. 315-320, 2000.

[8] M. R. Pranzatelli, E. D. Tate, A. L. Travelstead, and D. Longee, "Immunologic and clinical responses to rituximab in a child with opsoclonus-myoclonus syndrome," Pediatrics, vol. 115, no. 1, pp. e115-e119, 2005.

[9] M. R. Pranzatelli, E. D. Tate, A. L. Travelstead et al., "Rituximab (anti-CD20) adjunctive therapy for opsoclonusmyoclonus syndrome," Journal of Pediatric Hematology/ Oncology, vol. 28, no. 9, pp. 585-593, 2006.

[10] M. R. Pranzatelli, E. D. Tate, A. L. Travelstead, and J. A. Colliver, "Long-term cerebrospinal fluid and blood lymphocyte dynamics after rituximab for pediatric opsoclonusmyoclonus," Journal of Clinical Immunology, vol. 30, no. 1, pp. 106-113, 2010.

[11] T. Battaglia, E. de Grandis, M. Mirabelli-Badenier et al., "Response to rituximab in 3 children with opsoclonusmyoclonus syndrome resistant to conventional treatments," European Journal of Paediatric Neurology, vol. 16, no. 2, pp. 192-195, 2012.

[12] M. J. Burke and S. L. Cohn, "Rituximab for treatment of opsoclonus-myoclonus syndrome in neuroblastoma," Pediatric Blood and Cancer, vol. 50, no. 3, pp. 679-680, 2008.

[13] A. J. Grillo-López, C. A. White, C. Varns et al., "Overview of the clinical development of rituximab: first monoclonal antibody approved for the treatment of lymphoma," Seminars in Oncology, vol. 26, no. 5, supplement 14, pp. 66-73, 1999.

[14] A. Pestronk, J. Florence, T. Miller, R. Choksi, M. T. Al-Lozi, T. D. Levine et al., "Treatment of IgM antibody associated polyneuropathies using rituximab," Journal of Neurology Neurosurgery and Psychiatry, vol. 74, no. 4, pp. 485-489, 2003.

[15] J. H. Anolik, D. Campbell, R. E. Felgar et al., "The relationship of Fc $\gamma$ RIIIa genotype to degree of B cell depletion by rituximab in the treatment of systemic lupus erythematosus," Arthritis and Rheumatism, vol. 48, no. 2, pp. 455-459, 2003.

[16] P. Quartier, B. Brethon, P. Philippet, J. Landman-Parker, F. Le Deist, and A. Fischer, "Treatment of childhood autoimmune haemolytic anaemia with rituximab," The Lancet, vol. 358, no. 9292, pp. 1511-1513, 2001.

[17] B. H. Kushner, M. P. Laquaglia, M. A. Bonilla et al., "Highly effective induction therapy for stage 4 neuroblastoma in children over 1 year of age," Journal of Clinical Oncology, vol. 12, no. 12, pp. 2607-2613, 1994.

[18] M. R. Pranzatelli, E. D. Tate, I. Galvan, and A. Wheeler, "A controlled pilot study of piracetam for pediatric opsoclonusmyoclonus," Clinical Neuropharmacology, vol. 24, no. 6, pp. 352-357, 2001.

[19] E. D. Tate, T. J. Allison, M. R. Pranzatelli, and S. J. Verhulst, "Neuroepidemiologic trends in 105 US cases of pediatric opsoclonus-myoclonus syndrome," Journal of Pediatric Oncology Nursing, vol. 22, no. 1, pp. 8-19, 2005. 
[20] F. Ertle, W. Behnisch, N. A. al Mulla et al., "Treatment of neuroblastoma-related opsoclonus-myoclonus-ataxia syndrome with high-dose dexamethasone pulses," Pediatric Blood and Cancer, vol. 50, no. 3, pp. 683-687, 2008.

[21] M. R. Pranzatelli, E. D. Tate, S. Shenoy, and A. L. Travelstead, "Ofatumumab for a rituximab-allergic child with chronicrelapsing paraneoplastic opsoclonus-myoclonus," Pediatric Blood and Cancer, vol. 58, no. 6, pp. 988-991, 2012.

[22] M. R. Pranzatelli, A. L. Travelstead, E. D. Tate, T. J. Allison, and S. J. Verhulst, "CSF B-cell expansion in opsoclonus-myoclonus syndrome: a biomarker of disease activity," Movement Disorders, vol. 19, no. 7, pp. 770-777, 2004.

[23] J. B. Chung, A. D. Wells, S. Adler, A. Jacob, L. A. Turka, and J. G. Monroe, "Incomplete activation of CD4 T cells by antigen-presenting transitional immature B cells: implications for peripheral $\mathrm{B}$ and $\mathrm{T}$ cell responsiveness," Journal of Immunology, vol. 171, no. 4, pp. 1758-1767, 2003.

[24] M. R. Pranzatelli, E. D. Tate, E. R. Hoefgen, J. A. Swan, and J. A. Colliver, "Therapeutic down-regulation of central and peripheral B-cell-activating factor (BAFF) production in pediatric opsoclonus-myoclonus syndrome," Cytokine, vol. 44, no. 1, pp. 26-32, 2008.

[25] M. R. Pranzatelli, E. D. Tate, A. L. Travelstead, and S. J. Verhulst, "Chemokine/cytokine profiling after rituximab: reciprocal expression of BCA-1/CXCL13 and BAFF in childhood OMS," Cytokine, vol. 53, no. 3, pp. 384-389, 2011. 


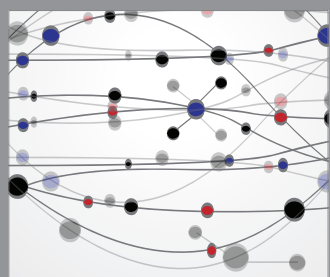

The Scientific World Journal
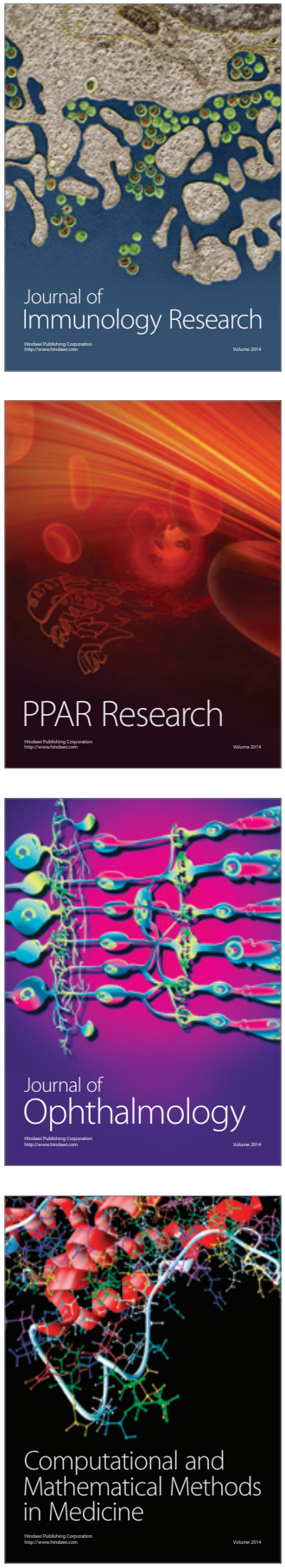

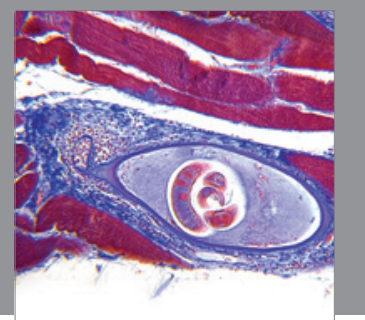

Gastroenterology

Research and Practice
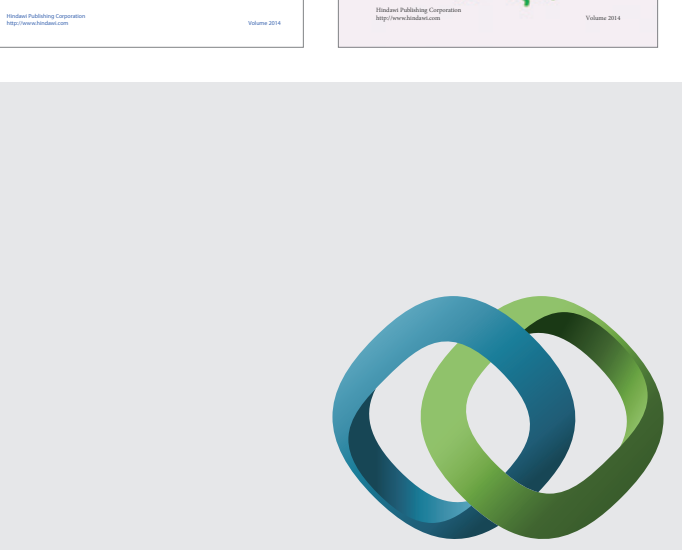

\section{Hindawi}

Submit your manuscripts at

http://www.hindawi.com
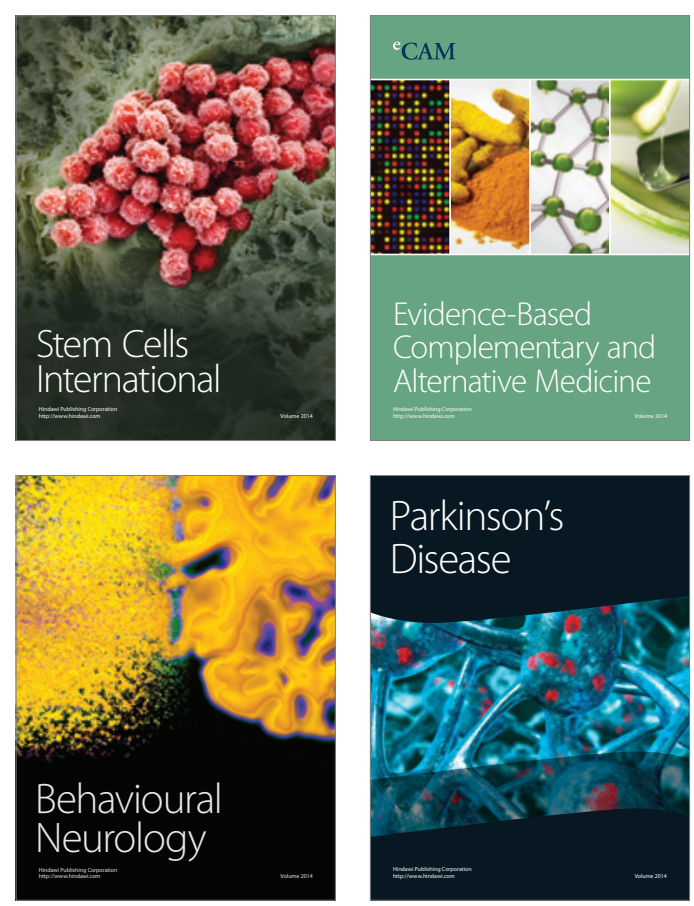

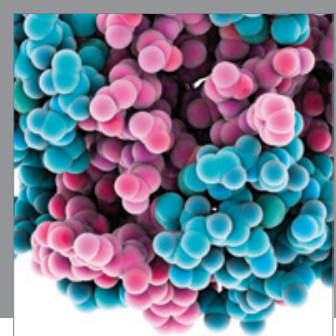

Journal of
Diabetes Research

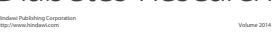

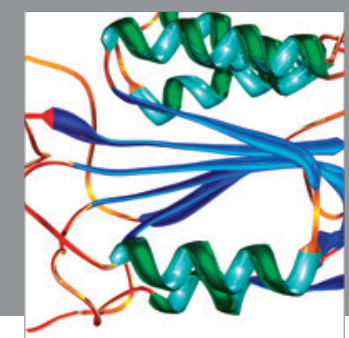

Disease Markers
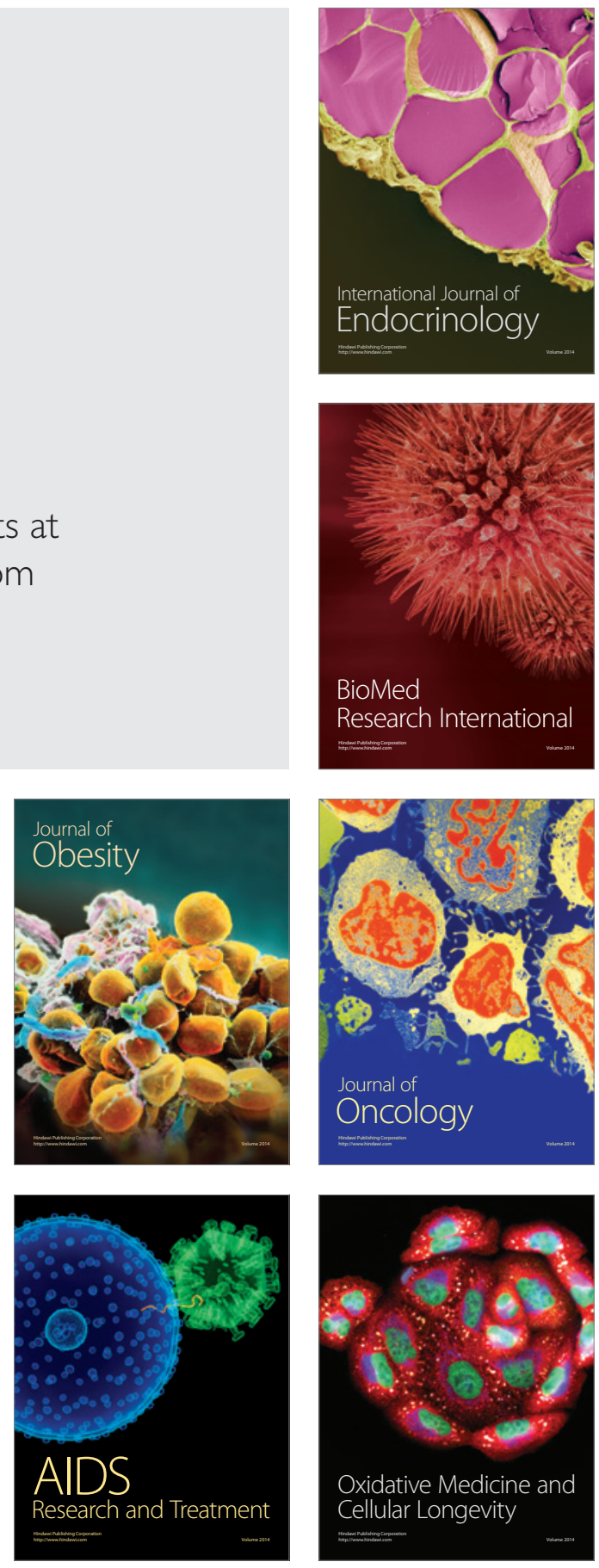